\title{
Teaching Art as Reasoned Perception: Aesthetic Knowing in Theory and Practice
}

\section{Richard Siegesmund}

In his First Meditation, Descartes (1641/1951) posed the skeptical question of how is it possible to know anything that we perceive with our senses, because we may in fact be dreaming. He concluded that we cannot trust our perceptions, that we must regard sensory experience as false, for all that we perceive may only be a dream world of our own subjective creation. Such a skeptical view was by no means a new philosophical position at the time of Descartes, but Descartes' reformulation of the skeptical argument has had an iconic power that has proved enduring. It leaves us with the idea that our perceptions, our senses, our feelings, are essentially untrustworthy. The information we gather through our senses is open to skeptical challenge, and we cannot make a claim for it as knowledge unless we can find another means of verification.

Cognition is defined as "the intellectual process by which knowledge is gained about perception and ideas" [Webster's Third New International Dictionary]. Cognition is the process of coming to know. Cognition is not static. It is a movement towards knowledge. While the end point of the cognitive process is knowledge, it is not where cognition begins. The process of cognition is a sorting out of information, the identification of what is pertinent, and categorization. The process includes also a manipulation of new information within the constraints of our previous knowledge. Cognition is an active, aggressive, act which fits an object into a subjective frame. Out of the process of cognition, we form beliefs regarding the validity of our knowledge.

Epistemology is the study and evaluation of our beliefs regarding what we hold to be valid knowledge. One of its concerns is the results of the cognitive process and examining the warrant for our beliefs in making those claims. Epistemology asks if claims to knowledge are trustworthy. Epistemology, with its concern for the outcomes of cognition, thereby has a legitimate claim to study, and evaluate the success of, the cognitive process itself.

By definition, perception is acknowledged as a part of the cognitive process, however, when we try to take a closer look at the role of perceiving and coming to know, the echoes of Descartes argument haunt us. The ghost is reflected in the Webster's definition--"knowledge... about perception." It is unclear where within the process of visual perception we can say how or when we have crossed a line into cognition. From an early age, the simple entertainment of illusionists teaches us that seeing is not alwavs a reliable basis for believing. Therefore, as cognition is a process of coming to know, where in the cognitive progression does visual perception play an active role? Is all of perception a part of the cognitive process, or is only a portion of perception cognitive? Is perception simply a tool for assembling raw data which feeds more subtle and sophisticated mental operations? Is there a point where visual perception ceases 
to play an active role in cognition as higher order mental skills take over? In what sense is cognition greater than perception? In what ways was Descartes right? Or, can visual perception make a direct link to knowledge--is there an epistemological base to perception? Descartes would have us believe that knowledge is always an end product achieved through the mediation of other cognitive processes separate from perception. The question then becomes, while visual perception may be cognitive, through its contributions to the cognitive process, is it ever epistemological--do we ever know?

My research interest is in understanding art education as a field of inquiry where the problems of cognition, perceiving and knowing are explicitly engaged. My interests are grounded in theory, but my interests are not limited to the theoretical. I am interested in how art is taught, and how theory is realized in practice. I am interested in art classrooms, and I am interested in the real, daily work of art educators

In my view, expert teaching in the arts is concerned with the developing the immediate experiential skills of perceiving. Perception is not simply the passive recognition of an image cast on a blank slate. Perception cannot be reduced to a photographic metaphor. Perception is an achievement of active intelligence requiring mental constructs permitting us to perceive (Dewey, 1916/Hanson, 1958). Expert art teaching is engaged in a dynamic relationship of instructing students in knowing what they see directly and providing a intellectual and experiential knowledge base allowing them to see. This dialogue between seeing and knowing, which is played out in an arts classroom through a multitude of experiential moments, can be described as "reasoned perception."

Through this term, a combination of reason and perception, I pose a challenge to classical formulations of what reason is for, since Plato, sense and thought, mind and body are considered to be separate entities. Reasoned perception suggests, contrary to Descartes, we do come to know our world through perception. Learning to perceive is not mere enrichment. It is not ancillary. I would disagree with other researchers (Gardner, 1983; Davis and Gardner, 1992) in attributing perception as an affect of a separate intelligence. It is a fundamental and basic part of cognition.

I do not believe there is anything particularly new about "reasoned perception." I believe it is the way many expert art teachers have taught for years. What may be new, or at least worth restating, is suggesting this instruction, based in the discipline of art, makes a legitimate and important contribution to cognition. Such a reconceptualization of the paradigm of cognition, may have specific and significant impact for the perception of the role of the arts within the overall school curricula.

It is important to note that in referring to art education both as a discipline and as a field of inquiry, my research question is consciously placed within a particular historical debate concerning the structure of an art curriculum (Barkan, 1966). While "reasoned perception" gives credit to the experiential nature of art education, there is also the suggestion that within art education there are specific 
bodies of knowledge to be mastered. Schwab (1969a) described these as "fields of systematic intellectual activity" (p. 2). In Schwab's view, each academic discipline represented a discrete approach, utilizing specific tools, to intellectual inquiry. 1 suggest whether it be the understanding of the components and interrelations of a color wheel, the experience of the explosion of concentrated watercolor pigment on a piece of water saturated paper, the historical awareness of specific artists who have sustained over time an interest in particular kinds of aesthetic problems, or the knowledge of a specific vocabulary within our language that can be utilized to explore and understand expressive form, these are all elements of a particular body of knowledge and are all significant components in the teaching of the discipline of art. This is how Bruner's (1960/1977) reference to "the teaching and learning of structure" (p. 12) within a subject area pertains to art education. Therefore, expert teaching in the arts is informed with a experiential knowledge of the structure of the discipline itself--not simply a structure of a lesson plan with precisely coordinated procedures, objectives and rubrics for assessment. Reasoned perception is firmly grounded in experiential ideas of discipline, structure and inquiry.

\section{Reasoned perception}

Reasoned perception is an ancient idea traceable back to the original Greek concept of Logos, the fundamental controlling principles of the universe. Marcuse (1955) suggests Logos' original meaning was much broader than our contemporary understanding which associates the word with reason. Logos originally refers to a fully realized self-aware state of being. Logos is an ontological condition. A part of Logos was aisthanesthai-the ability to perceive.

Aisthanesthai is the root for the English word aesthetics. To pursue the etymology further, within the Greek language, verbs are conjugated in one of three ways: 1) as an action that an individual initiates, 2) as an action that is done to an individual, or 3 ) an action that is simultaneously both initiated and incurred. Aisthanesthai is conjugated in the third fashion, thus creating a meaning that reflects a dynamic state between subject and object with each effecting (not simply affecting) the other. Therefore, it can be argued Logos originally incorporated the capacity to appreciate the sense of qualities and distinctions of an object within the subject's perception. Moreover, appreciation was an action which required active mental engagement by the viewer in the process of observing an object which possessed its own tangible presence independent of the viewer.

Plato, however, argued that Logos should properly be seen as utilization of logic over base instincts (his pejorative term for perception). The privileged place Plato assigned to logic initiated a distinction between mind and body. Later, Aristotle contended that Logos is rationality, thereby solidifying the mind-body distinction. Thereafter in Western thought, from Aristotle to Hegel, and into the present day, reason is a struggle of mind over sense.

Reasoned perception seeks to reverse this Western historical trend and reclaim a role for the senses in the exercise of rationality, thereby recapturing a pre-Aristotelian concept of Logos. Reasoned perception does not reject the 
achievements of rationality. On the contrary, it seeks to incorporate them into a new paradigm that attempts to overcome the mind/body dualism.

Despite the dominance of the mind/body dualism in Western philosophical thought, reasoned perception has been, and continues to be, a continuing philosophical concern. For example, one of the abiding themes in the philosophical work of Immanuel Kant (1929/1965) is the relationship of the individual to objects existing in an external world. In the Critique of Pure Reason(1787/1965), Kant's concept of anschauung, deals with the phenomenon of our apprehension of physical entities having an objective reality yet are simultaneously created by our perception of them. Kant did not consider this to be aesthetic since the process of conceptualization --cognition--was engaged in this experience. In the Critique of Judgment(1790/1987, Kant suggested aesthetic experience occurred by our perception of objects which by their nature possessed no attributes, no concepts, by which they could be conceptually categorized, thereby triggering the free play of the imagination, and resulting in--requiring--a reconstruction of our conceptual categories.

Continuing into the 20th century, from Martin Heidegger (1971) and Theodore Adorno (Horkheimer and Adorno, 1944/1994) in Germany to John Dewey (1916, 1929/1988, 1934/1989) and Maxine Greene (1995) in America, there is a concern to expand what counts within epistemology while preserving the accomplishments of the rationalist tradition. Dewey (1929/1988) suggested that knowledge existed only in relationship to objects, not as fixed meanings that could exist outside of time and space. He observes that "physical time designates arelation of events, not the inherent property of objects." (p. 116). In Art as Experience(1934/1989), he spoke to the qualities of those relationships as contributing to cognition:

To think effectively in terms of relations of qualities is as severe a demand upon thought as to think in terms of symbols, verbal and mathematical. Indeed, since words are easily manipulated in mechanical ways, the production of a work of genuine art probably demands more intelligence than does most of the so-called thinking that goes on among those who pride themselves on being "intellectuals." (p. 52)

The Gestalt psychologist Rudolph Arnheim (1969) is similarly concerned with these experiential qualities of relationships. He suggests that our perceptual experience is not antecedent to cognition, nor does perception merely supply the data which other cognition mechanisms process, but that perception itself is a cognitive act:

cognitive operations called thinking are not the privilege of mental processes above and beyond perception but the essential ingredients of perception itself. I am referring to such operations as active exploration, selection, grasping of essentials, simplification, abstraction, analysis and synthesis, completion, correction, comparison, problem solving, as well as combining, separating, putting in context. These operations are not the prerogative of anyone mental function.... There is 
no basic difference in this respect between what happens when a person looks at the world directly and when he sits with his eyes closed and "thinks." (p. 13)

Gestalt experiences are rich, complex, and not transparently knowable or describable in clear propositional terms. Lakoff and Johnson (1980) suggest metaphors are records of experiential gestalts. Each gestalt is a framework with which to see, a grid on which we can construcl our own knowledge-- an empirical grid woven from experience. Our perceptual world is key to our experiential world which we name and quantify. Perceiving itself is an act of differentiation. We need the grid to construct meaning in it provides a frame for selecting qualities out of undistinguished commonalty. The construction of knowledge, or more accurately the re-construction of knowledge from discriminating perception is a process of re-collecting and recombining. We reconstruct our metaphors into meaning.

Working out of the Gestalt tradition, cognitive psychologists (Spelke. E., Gutheil, $G$. and Van de Walle. G, 1996) have done extensive tests with infants to understand what infants can learn through perception before they have developed the cognitive capacity to categorize and classify. Their work shows the making of meaning is not a merely linguistic construction of connecting referent to symbol. Our ability to build meaning from experiential gestalts is present at birth.

The work of these philosophers, psychologists, linguists and neuroscienctists are all part of a substantial historical project to mend the stark separation of traditional epistemology which sought to separate mind from body through ontology, the science of being. It seeks not to see things as separate, but understand them as existing in relationships. There is a new appreciation, discovery --a contemporary re-collection--of logos. Within this project, art education has a role in this project as a process of training the eye to differentiate, of learning to make reasoned judgments, and being aware of criteria on which those judgments are based to the end of creating personal frameworks on which we build individual meaning.

\section{Theory and Classrooms}

As I stated at the beginning of this paper, my interest in art education is not simply theory driven. Theory plays a role in the structure of curriculum, but curriculum is profoundly shaped by pedagogy. Consequently, my concern extends to what happens in a classroom led by expert practitioners. In my research, I seek to identify examples of purposeful teaching of reasoned perception. Purposeful teaching is categorized by Shulman's (1986) as the skillful implementation of three forms of knowledge which inform the craft of teaching: "knowledge of rules of principles, knowledge of particular cases, and knowledge of ways to apply appropriate rules to properly discerned cases." (p. 31) Shulman suggests, beyond the content of the discipline, expert teaching involves a dynamic interaction between teacher and student. Expert teaching incorporates adopting appropriate pedagogical moves (Shulman's "principles") to knowledge of students (Shulman's "particular cases"). Such expertise, is a 
prerequisite to the ability to teach a discipline. Consequently, purposeful art educators who teach utilizing reasoned perception would be able to articulate a strong theoretical foundation for their teaching and demonstrate in their classroom practice a wide repertoire in applying "appropriate rules to properly discerned cases."

Traditionally, much of the assessment, for both students and teachers, of what goes on in an art class, centers on an evaluation of the objects that are produced. My research is less concerned with objects and is more concerned with teaching and learning in a dynamic creative environment. As a part of this interest, I want to look at how students engage the creative process in their work; however, I want to carefully separate this concern from an investigation into products--particularly the aesthetic valuing of artistic objects. In doing so, I do not mean to suggest the products of arts education, and aesthetic valuing, are unimportant; however, I believe the aesthetic valuing of finished products as a principle form of student assessment is not a primary concern of teaching art as reasoned perception.

As I am choosing not to use aesthetic valuing of artistic objects as lens for looking at art classes, how then will I recognize an exemplar classroom? What is the content that would categorize an arts classroom where reasoned perception is taught? What is pedagogical environment where that content would be delivered? Green (1983) describes classroom as communicative environments. Although Green was articulating a linguistic perspective on research, her method, with it emphasis on dynamic constructed activities, captures the feel of creative process which is valued in art education:

From this perspective, events evolve during interactions as teachers and students work together to meet instructional goals. Therefore, classroom events... are dynamic activities constructed by teachers and students as they process, build on, and work with both their own and the others' messages and behaviors. (p. 357)

Although this environment may be dynamic, it would be a mistake, especially in an art education context, to consider it arbitrary. Gage (1978) and Schwab (1983) suggest an educationally constructive, interactive process is structured by rules. I suggest these models can be applied to an arts classroom concerned with creative process. Creative process is purposeful and directed. As Schwab observes:

Every art, whether it be teaching, stone carving or judicial control of a court of law...has rules, but knowledge of the rules does not make one an artist. Art arises as the knower of the rules learns to apply them appropriately to the particular case. Application, in turn, require acute awareness of the particularities of that case and ways in which the rule can be modified to fit the case without complete abrogation of the rule. In art, the form must be adapted to the matter. Hence the form must be communicated in ways which illuminate its possibilities for modification. (p. 265) 
For Schwab, expert teaching is governed not simply by pedagogical rules, but rules that arise out of the discipline itself. Schwab (1969a, 1969b) suggests teaching and learning as structured forms of inquiry within disciplines. in appealing to the knowledge of a discipline, there is an explicit suggestion that there are certain kinds of knowledge. In effect, there are territories of knowledge. Each territory has a contribution to make to our understanding. Schwab describes "fields of systematic intellectual activity (1969a, p. 2)." There are bounded fields, and within each field there is a particular kind of knowledge that is worth knowing. By the use of words like systematic and structure, it is suggested these are fields best explored with guidance. Teaching, therefore, is an introduction to the conventions and structures of each field.

\section{The Structure of Practice}

Schwab proposes a specific procedure for teaching the structure of inquiry within a field of knowledge. He calls the process of this inquiry "reflexive scrutiny." (1969b p. 65) and offers a description of this process as the "means by which to identify and segregate the appropriate and inappropriate and to show that they are the one or the other." But this is not simply a process of naming and categorization. Schwab speaks to the need of the students to experience the discipline (p. 51). To know the subject matter is not enough. Schwab suggests while the experience of a discipline can only be learned through intimate knowledge of the structure of a discipline itself, that experience can only be achieved by avoiding a "rhetoric of conclusions." (p. 52). Schwab claims through his method of enquiry not just knowledge of the data within a discipline is achieved, but the ontological relation, an experience, of the discipline is achieved as well.

Schwab contends enquiry is a process of conceiving a problem, planning a specific approach towards dealing with the problem and then marshaling and examining the data pertinent to the approach. The products of enquiry, the object created --what would commonly be called the conclusions-- are not uninteresting, but they cannot become rhetorical endgames. These conclusions--these objects-"will not appear alone and unchallenged." (p.52) In fact, "in many instances, they will be members of a pair or a trio of enquiries, treating a similar subject matter in different terms, posing different problems, seeking different data and argument." (p. 52) The concept of teaching is not as direct transmission of facts and figures which are poured into empty vessels, towards the end of reinforcing a predetermined set of conclusions, but a process through which "the sense and soundness of materials are dealt with by students and instructor in concert." (p.53)

Following Schwab's "Arts of Recovery", I suggest there are six ways (rules) in which teaching for reasoned perception can be identified in an arts classroom:

1) Students are directed to observe their world and assemble specific observations through the use of particular visual media.

2) There is an emphasis of process over product. Products produced

Marilyn Zurmuehlen's Working Papers In Art Education 1996-1997 
through the assemblage of observations are not presented as autonomous objects for aesthetic enjoyment, rather they are presented as embodiments of ideas to be shaped, focused and sharpened. It is the process of embodying ideas which interests the practitioner of reasoned perception, not a traditional aesthetic appreciation of an object or a performance.

3) An arts class emphasizing an open exchange of ideas about art. Within reasoned perception there is an expectation works of art or performances were motivated by an idea. This idea was distinctly embodied in the medium in which the artist or the performer chose for their expression. Although the idea does not possess a precise direct referent in language, reasoned perception suggests both the artist and the audience can meaningful discuss the ideas the work of art is dealing with. Most importantly, the creator of the work of art can consciously embody an idea in a work of art--a symbolic art. This idea is not allegorical. It has a direct meaning in itself; yet it is the product of the creator.

4) Not only is it possible to use language to explore ideas underlying works of art and performances, there is an expectation language and discourse are appropriate tools for increasing our understanding of the ideas embodied in art. This discourse enhances our capacity to use the arts in the expression of our own ideas. This means significant portions of class time are dedicated to student discussion.

5) Works of art and performances have structures which can be analyzed and compared. Out of this analysis, judgments can be made. Reasons can be offered to support such judgments.

6) To understand works of art requires attention to perceptual detail. Works of art and artistic performance require consideration of the unexpected and the unknown. They present the possibility of conceiving the world in a different paradigm. The arts pose the potential of seeing the world through new lenses. Therefore students must be trained to perceive the unexpected, ground their inquiry in detail, and avoid generalizations. Attention to perceptual detail leads back to the assemblage of specific observations and so creates a natural loop of discourse and growth.

For Schwab, the rules can only be implemented by a teacher knows a discipline "through and through." Schwab defines this as having the "syntax, vocabulary, and organization appropriate to the meaning [the materials of the class] are to convey." (1969b, p.52) Furthermore, this enquiry must be guided by an alert sensitivity to what each student says and does. Most importantly to maintain the dynamic of enquiry, "the instructor's aim must be, as far as possible and especially in the beginning, to 'honor' each student response." (p. 67)

\section{The Passion and Concern of the Discipline}

Teaching is more than multiple sets of pedagogical moves specific to a discipline and fully translatable to a lesson plan. Teaching requires a pedagogical means of finding an embodiment to the passion of a discipline. The embodiment 
of the passion of the discipline is a much more vivid description than knowing a discipline through and through, although I don't believe this distorts Schwab's meaning. Passion speaks to the experiential character of knowledge that is more than simply knowing but extends to caring about content of the discipline.

Teaching would then require a particular kind of passion to explore a field of inquiry. Passion suggests the process of dealing with the sense and soundness of content is not a detached, abstract task of demarcating a territory, but there is a physical and emotional quality to inquiry. Knowledge requires the embodiment of the sensory experience of inquiry. There is a physical sensuousness in our moving in a particular intellectual territory. The teacher embodies the passion, the sensuality, of the discipline, models it and allows the opening where this passion can be experienced by students. In so doing, the students, if they want, can make this passion their own. Passion, the sensuousness of teaching, is not limited to the experiential encounter with the disciple but is part of the interaction between teacher and student. Passion lies at the heart of the moment of transfer of knowledge. My research would be particularly interested in looking for these occurrences of teaching which invite and engage the student in experiential moments, and entered through the act of perception. Experiential moments are those engaging both the mind and the body.

Besides the embodiment of knowledge, Schwab speaks of good teaching as engaging and honoring students. There is a responsibility of the teacher to be concerned with the integrity of the subject matter itself, to be connected to a field of ideas, and to care enough for their students so they have an opportunity to connect with this concern as well. Maxine Greene (1995) has suggested, teachers need to recognize that epistemology goes beyond naming and embraces caring and concern. Therefore, a classroom where art is taught as reasoned perception would show sensory experience is a part of the content, and the feelings of students an integral component pedagogical concern.

\section{Conclusion}

My research can be broken down into two broad concerns: 1) an explication of the concept of reasoned perception, and 2) an analysis of how art is taught as reasoned perception, limited to a set of specific cases. Most importantly, I am concerned with the content of teaching. To do this, I want to be in classrooms and watch exemplar teachers teaching. In those classroom, I do not wish to be simply an ethnographic reporter because I am equally concerned with issues of worth. I want to do more than accurately record what is happening; I also want to reflect upon the intentions of the teachers and the worth of what is being taught. Why have particular teachers chosen to teach the arts in a particular manner? What is it they hope to teach? With this perspective I would compare how it is these teachers actually appear to teach, and what it is that students appear to learn.

In such classrooms, expert art educators address on a daily basis Descartes' skeptical question of how is it possible to know anything that we 
perceive with our senses. It is the challenge expert art educators confront in each of their classroom for art education is a field of inquiry in which the tools of the discipline are experiential feelings and sensory concepts. In response to Descartes, when art education is purposefully taught, with passion and concern-as reasoned perception--it can provides students insight into exquisitely varied forms of artistic representation providing us access to Descartes ultimate goal: knowledge of our world.

\section{References}

Arnheim, R. (1969). Visual thinking. Berkeley: University of California Press.

Barkan. M (1966). Curriculum problems in art education. In E. Mattil (Director), A seminar in art education for research and development (USOE Cooperative Research Project No. V-022) (pp. 240-255). University Park, PA: The Pennsylvania State University.

Bruner, J. (1977). The process of education. Cambridge: Harvard University Press. (Original work published 1960).

Davis, J \& Gardner. H. (1992). The cognitive revolution: Consequences for the understanding and education of the child as artist. In B. Reimer and R.A. Smith (Eds.) The arts, education, and aesthetic knowing, (pp. 92-123). Chicago, IL: National Society for the Study of Education.

Descartes, R. (1951). Meditations on first philosophy (L. J. Lafleur, Trans). New York: Macmillan. (Original work published 1641).

Dewey. J (1916). Democracy and education. New York: The Free Press.

Dewey, J. (1988). The quest for certainty. Carbondale, IL: Southern Illinois University Press. (Original work published 1929).

Dewey, J. (1989). Art as experience. Carbondale, IL: Southern Illinois University Press. (Original work published 1934).

Gage, N. (1978). The scientific basis of the art of teaching. Chicago: Rand McNally.

Gardner, H. (1983). Frames of mind. New York: Basic Books.

Green, J. (1983). Teaching and learning: A linguistic perspective. Elementary School Journal, 83(4), 353-391.

Greene, M. (1995). What counts as Philosophy of education. In Konli, W. (Ed.) Critical conversations in philosophy of education. New York: Routledge. 
Hanson, N. R. (1958). Patterns of discovery. Cambridge: Cambridge University Press.

Heidegger, M. (1971). Poetry, language, thought (A. Hofstadter, Trans.). New York: Harper \& Row.

Horkheimer, M and Adorno, T (1994). Dialectic of enlightenment. New York: Continuum. (Original work published 1944).

Kant, I. (1965). Critique of pure reason (N. K. Smith, Tans.). New York: Macmillan. (Original work published 1787).

Kant, I. (1987). Critique of judgment (W. Pluhar, Trans.).Indianapolis, IN: Hackett. (Original work published 1790).

Lakoff, G. and Johnson, M (1980). Metaphors we live by. Chicago: University of Chicago Press.

Marcuse, H. (1955). Eros and civilization. Boston: Beacon Press.

Schwab, J. (1969a). The practical: A language for curriculum. School Review, $78(5)$.

Schwab, J. (1969b). Coliege curriculum and student protest. Chicago: University of Chicago Press.

Schwab, J. (1983). The practical 4: Something for curriculum professors to do. Curriculum inquiry, 13(3), 239-265.

Shulman, L. (1986). Paradigms and research programs in the study of teaching: A contemporary perspective. In Wittrock, M.C. (Ed.) Handbook of Research on Teaching, Third Edition. New York: Macmillan.

Spelke, E., Gutheil, G. and Van de Walle, G (1996). The development of object perception. In S. Kosslyn and D. Osherson (Eds.), Visual cognition: An invitation to cognitive science, Second Edition (pp. 297-330). Cambridge, MA: The MIT Press. 